\title{
Chelidonine suppresses migration and invasion of MDA-MB-231 cells by inhibiting formation of the integrin-linked kinase/PINCH/ $\alpha$-parvin complex
}

\author{
OKHWA KIM ${ }^{1}$, CHEOL HWANGBO ${ }^{1}$, JUNHYEONG KIM ${ }^{1}$, DONG-HAO LI ${ }^{2}$, \\ BYUNG-SUN MIN $^{3}$ and JEONG-HYUNG LEE ${ }^{1,2}$
}

\begin{abstract}
${ }^{1}$ Department of Biochemistry, College of Natural Sciences, Kangwon National University, Chuncheon, Gangwon-do 200-701, Republic of Korea; ${ }^{2}$ Key Laboratory of Natural Resources of Changbai Mountain \& Functional Molecules, Yanbian University, Yanji, Jilin 133002, P.R. China; ${ }^{3}$ College of Pharmacy, Catholic University of Daegu,
\end{abstract}

Gyeongsan, North Gyeongsang 712-702, Republic of Korea

Received December 5, 2013; Accepted August 12, 2014

DOI: $10.3892 / \mathrm{mmr} .2015 .3621$

\begin{abstract}
Metastasis is the primary cause of cancer-associated mortality. The ternary IPP complex of integrin-linked kinase, PINCH and parvin functions as a signaling platform for integrins, which modulate numerous cellular processes including cell migration and invasion. Chelidonine, isolated from Chelidonium majus, is a benzophenanthridine alkaloid that exhibits anticancer properties; however, the anti-migratory and anti-invasive effects of chelidonine remain unknown. The aim of the present study was to investigate the inhibitory effects of chelidonine on migration and invasion of MDA-MB-231 human breast cancer cells, and to determine the underlying mechanisms. Chelidonine was shown to inhibit the migration and invasion of MDA-MB-231 cells in a concentration-dependent manner, without affecting the cell viability. Chelidonine did not significantly inhibit the adhesion of the cells to type 1 collagen (COL-I), however it did affect cell spreading and reorganization of the actin cytoskeleton. Chelidonine also inhibited COL-I-induced protein kinase B (Akt) activation and translocation to the plasma membrane, however, it did not significantly inhibit the activation of focal adhesion kinase. Notably, chelidonine treatment significantly inhibited COL-I-induced formation of the IPP complex and activation of IPP downstream signaling molecules, such as extracellular signal-regulated kinase (ERK)1/2. These results suggest that chelidonine exhibits anti-migratory and anti-invasive effects in MDA-MB-231 cells, by suppressing COL-I-induced inte-
\end{abstract}

Correspondence to: Professor Jeong-Hyung Lee, Department of Biochemistry, College of Natural Sciences, Kangwon National University, Hyoja 2-Dong, Chuncheon, Gangwon-do 200-701, Republic of Korea

E-mail: jhlee36@kangwon.ac.kr

Key words: chelidonine, migration, invasion, IPP complex, integrins grin signaling, through inhibiting the formation of the IPP complex and subsequent down-regulation of IPP downstream signaling molecules, such as Akt and ERK1/2. These results suggest that chelidonine may be a potential therapeutic agent against metastasis of invasive human cancer cells.

\section{Introduction}

Metastasis is the leading cause of morbidity and mortality associated with cancer. The development of metastasis consists of numerous processes, in which cancer cells initially detach from the primary tumor, invade the surrounding tissues and intravasate into blood and/or lymphatic systems. This is followed by extravasation from the vasculature and subsequent colonization of target organs (1). The extracellular matrix (ECM) provides both structural support and extracellular cues that regulate invasive tumor growth. Tumor-associated changes in the ECM contribute to cancer progression (2). Cell migration involves the assembly and disassembly of focal adhesions. The migration of cells is stimulated extracellularly and is initiated by integrins and intracellular signaling proteins, which are located within focal adhesions $(2,3)$. Integrins are $\alpha$ and $\beta$ heterodimeric cell-surface receptors that mediate cell-ECM interactions, and have important roles in the regulation of normal and tumor cell migration and survival $(2,3)$. The binding of a ligand to the extracellular integrin domain induces conformational changes and integrin clustering, that results in the activation of signaling cascades and recruitment of multi-protein complexes to focal adhesions (4). Subsequently, integrins lacking kinase activity transmit signals through a variety of intracellular protein kinases and adaptor molecules, including focal adhesion kinase (FAK), integrin-linked kinase (ILK) and paxillin (5-7).

ILK has a central role in mediating signal transduction, initiated by cell-ECM interactions. This leads to the regulation of numerous biochemical processes, including proliferation, survival, differentiation, migration, invasion and angiogenesis (8). ILK was initially described as an integrin $\beta 1$ subunit-binding protein, with involvement in kinase signaling 
pathways (5). However, previous studies have demonstrated that ILK is a pseudokinase that acts as a distinct adaptor protein linking integrin and $\alpha$-parvin $(9,10)$. Structurally, ILK is comprised of an $\mathrm{N}$-terminal ankyrin repeat domain and a C-terminal kinase-like domain $(10,11)$. Through the ankyrin repeat domain, ILK binds to PINCH1 (12). The kinase-like domain of ILK interacts directly with other components of integrin-based adhesion plaques, including $\alpha$-parvin $(9,10,13)$. ILK, PINCH1, and $\alpha$-parvin form the ternary complex IPP, which has emerged as an essential constituent of integrin-containing adhesion sites. IPP functions both as a structural complex, that connects integrins to the actin cytoskeleton, and as a signaling platform, that modulates numerous cellular processes $(6,8)$. The IPP complex is a central constituent of $\beta 1$ and $\beta 3$ integrin-containing adhesion sites, where it regulates numerous signaling pathways, including Akt, extracelullar signal-regulated kinase (ERK)1/2, and $\operatorname{Rac1}(6,8,13)$.

Chelidonine is a major benzophenanthridine alkaloid derived from the plant extract of Chelidonium majus, which is also known as the greater celandine (family Papaveraceae), and is widely distributed in Europe and Asia. The plant extract exhibits notable antitumor and antiviral activities (14). Chelidonine is the major component of the anticancer drug Ukrain, which is a semisynthetic derivative of C. majus alkaloids and has antitumor activity (15). This alkaloid has been shown to induce apoptosis of primary human uveal melanoma cells (16); arrest mitosis through the inhibition of tubulin polymerization and activation of the stress-activated protein kinase/c-Jun N-terminal protein kinase (17); and down-regulate the expression of telomerase in HepG2 cells (18). The effects of chelidonine on cell migration and invasion, however, have not yet been determined. The aim of the present study was to explore whether chelidonine inhibited the migration and invasion of MDA-MB-231 human breast cancer cells, and to further elucidate the underlying mechanisms.

\section{Materials and methods}

Cell culture and reagents. MDA-MB-231 human breast cancer cells were purchased from the American Type Culture Collection (Manassas, VA, USA). The cells were maintained in RPMI-1640 medium, supplemented with $100 \mathrm{U} /$ $\mathrm{ml}$ penicillin and $100 \mu \mathrm{g} / \mathrm{ml}$ streptomycin (Invitrogen Life Technologies, Carsbad, CA, USA) and 10\% heat-inactivated fetal bovine serum (HyClone Laboratories, Inc., Logan, UT, USA), in a humidified $5 \% \mathrm{CO}_{2}$ atmosphere at $37^{\circ} \mathrm{C}$. The chelidonine used for the present study was isolated from $C$. majus as described by previous methods (19). The chemical structure of chelidonine is shown in Fig. 1. The purity of the compound was determined to be $>98 \%$, by high performance liquid chromatography analysis. HPLC was performed using a Gilson UV/VIS 156 system (Gilson Inc., Middleton, WI, USA), in reverse phase mode on an Agilent Eclipse XD8-C18 $(5 \mu \mathrm{m} ; 4.6 \times 250 \mathrm{~cm})$ column (Agilent Technologies, Santa Clara, CA, USA) at an elution rate of $1 \mathrm{ml} / \mathrm{min}$, in the gradient $15-80 \%$ of acetonitrile in $10 \mathrm{mM} 1$-hexane sulphonic acid sodium. The chelidonine was solubilized in $100 \%$ dimethyl sulfoxide (DMSO) and used at a final concentration of $<0.05 \%$ DMSO. Antibodies against phospho-Akt (Ser473), Akt,

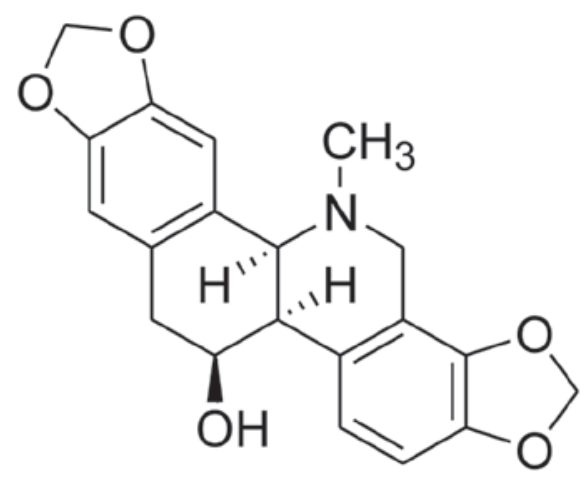

Figure 1. The chemical structure of chelidonine.

ERK1/2, phospho-ERK1/2 (Thr202/Tyr204), phospho-FAK (Tyr397), FAK, and ILK were obtained from Santa Cruz Biotechnology, (Santa-Cruz, CA, USA). Antibodies against $\alpha$-tubulin and PINCH1 were from Sigma-Aldrich (St. Louis, MO, USA). Protein A/G agarose beads and antibodies against GAPDH, ErbB2, and $\alpha$-parvin were obtained from Santa Cruz Biotechnology Inc. (Dallas, TX, USA). Fibronectin and type 1 collagen (COL-I) were purchased from BD Biosciences (Franklin Lakes, NJ, USA). Fluorescein isothiocyanate (FITC)-conjugated phalloidin was from Enzo Life Sciences (San Diego, CA, USA).

Cell viability assay. The cytotoxic activity of chelidonine was determined using an MTT-based colorimetric assay. Briefly, the cells $\left(1 \times 10^{4}\right.$ cells/well) were seeded in 96-well plates and allowed to grow for $24 \mathrm{~h}$. Chelidonine was added to the wells at the following concentrations: $0,1,3,10 \mu \mathrm{m}$. Following an additional $24 \mathrm{~h}$ incubation, the MTT solution $(5 \mathrm{mg} / \mathrm{ml})$ was added and the cells were incubated for $4 \mathrm{~h}$. The experiment was performed in triplicate and the cell viability was presented as a percentage of the control.

Immunoprecipitation and western blotting. Immunoprecipitation and western blotting were performed as previoulsy described $(20,21)$. Briefly, the cells were lysed in lysis buffer, containing $50 \mathrm{mM}$ Tris- $\mathrm{HCl}$ (pH 7.4), $150 \mathrm{mM} \mathrm{NaCl}$, $1 \mathrm{mM}$ EDTA, $5 \mathrm{mM}$ sodium orthovanadate, $1 \%$ NP40 and a protease inhibitor cocktail (BD Biosciences), and centrifuged at $22,000 \mathrm{x} \mathrm{g}$ for $10 \mathrm{~min}$ at $4^{\circ} \mathrm{C}$. A total of $25 \mu \mathrm{g}$ protein per lane was separated by sodium dodecyl sulfate (SDS)-polyacrylamide gel electrophoresis and transferred onto a polyvinylidene difluoride membrane (Millipore, Bedford, MA, USA.). The membrane was blocked with 5\% non-fat milk for $2 \mathrm{~h}$ and subsequently incubated with the corresponding primary antibody (1:1,000 dilution) overnight at $4^{\circ} \mathrm{C}$. Following washing and binding of an appropriate secondary antibody (1:5,000 dilution) coupled to horseradish peroxidase for $2 \mathrm{~h}$ at room temperature, the signals were visualized by enhanced chemiluminescence according to the manufacturer's instructions (Animal Genetics Inc, Kyonggi-do, Korea). For the immunoprecipitation, equal quantities of cell lysate were incubated with the appropriate antibodies, followed by an incubation with protein $\mathrm{A} / \mathrm{G}$ agarose beads. The immunoprecipitates were extensively 
washed and the eluted precipitates were resolved, transferred and probed with the appropriate antibodies.

Cell fractionation. The cells were washed with phosphate-buffered saline (PBS), incubated for $20 \mathrm{~min}$ in hypotonic lysis buffer (50 mM Tris-HCl, pH 7.0, 1 mM EDTA, 0.1\% $\beta$-mercaptoethanol, $5 \mathrm{mM}$ sodium orthovanadate, protease inhibitors cocktail) and $1 \mathrm{ml}$ of the protein extract was lysed using a pre-chilled Dounce homogenizer (Thomas Scientific, Swedesboro, NJ, USA), with a tight-fitting pestle (15 strokes). Unbroken cells and nuclei were pelleted at $1,000 \mathrm{x}$ g at $4^{\circ} \mathrm{C}$ for $10 \mathrm{~min}$, the supernatants were further centrifuged at $21,000 \mathrm{x} \mathrm{g}$ at $4^{\circ} \mathrm{C}$ for $45 \mathrm{~min}$. The pellets, containing the cellular membranes, were washed three times in hypotonic lysis buffer and resuspended in lysis buffer prior to western blot analysis.

Cell migration and invasion assays. The cell migration and invasion assays were performed using a modified Boyden chamber ( $8 \mathrm{~mm}$ pore size; Corning Costar, Cambridge, MA, USA) as described by previous methods $(20,21)$. Briefly, the lower surface of the filters were coated with COL-I or fibronectin as a chemoattractant. The upper surface of the filter was coated with Matrigel ${ }^{\mathrm{TM}}$ (BD Biosciences) for the invasion assay, or left uncoated for the migration assay. MDA-MB-231 cells were seeded at a density of $5 \times 10^{4}$ cells in $100 \mu \mathrm{l}$ RPMI, containing $0.5 \%$ bovine serum albumin (migration) or RPMI, containing 10\% FBS (invasion) in the upper compartment of transwell. The lower compartment contained $800 \mu \mathrm{l}$ RPMI, containing $10 \%$ FBS. Following incubation for $8 \mathrm{~h}$ (migration) or $24 \mathrm{~h}$ (invasion) at $37^{\circ} \mathrm{C}$ in $5 \% \mathrm{CO}_{2}$, the cells which had not penetrated the filter were completely wiped away using a cotton swab and the cells which had migrated to the lower surface of the filter were fixed with methanol. The cells were subsequently stained and counted in $\geq 5$ randomly selected microscopic fields (magnification, $\times 100$ ) per filter using an Olympus CKX41 inverted microscope (Olympus, Tokyo, Japan).

Adhesion and spreading assays. The cell adhesion assays were carried out using 96-well tissue culture plates. The plates were coated with $10 \mu \mathrm{g} / \mathrm{ml}$ of COL-I overnight at $4^{\circ} \mathrm{C}$. Each well was rinsed with $1 \mathrm{X}$ PBS and blocked with PBS supplemented with $0.1 \%$ bovine serum albumin for $1 \mathrm{~h}$. The cells were plated at a density of $2 \times 10^{4}$ cells/well. Following a $1 \mathrm{~h}$ incubation, the unbound cells were removed from the wells by gentle aspiration and washed three times with PBS. The attached cells were quantified by measuring the acid phosphatase activity. Briefly, the attached cells were treated with lysis buffer $(0.1 \mathrm{M}$ sodium acetate, $\mathrm{pH} 5.0,0.1 \%$ triton $\mathrm{X}-100)$ containing $5 \mathrm{mM}$ p-nitrophenyl phosphate and incubated for $1 \mathrm{~h}$ at $37^{\circ} \mathrm{C}$, followed by the addition of $1 \mathrm{M} \mathrm{NaOH}$. The absorbance was measured at $405 \mathrm{~nm}$ using a microplate reader.

For the spreading assay, the cells were seeded into a 24-well plate coated with $10 \mathrm{mg} / \mathrm{ml}$ of COL-I( $1 \times 10^{5}$ cells/well $)$ and incubated for $1 \mathrm{~h}$.Following theincubation, the cells were fixed in $3.7 \%$ formaldehyde. The proportion of spread cells was determined using a light microscope. Non-spread cells were observed as small, round cells with little or no membrane protrusions, whereas spread cells were observed as large cells with exten-
A

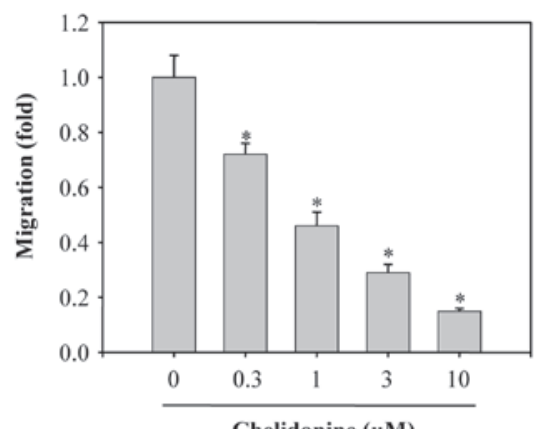

B

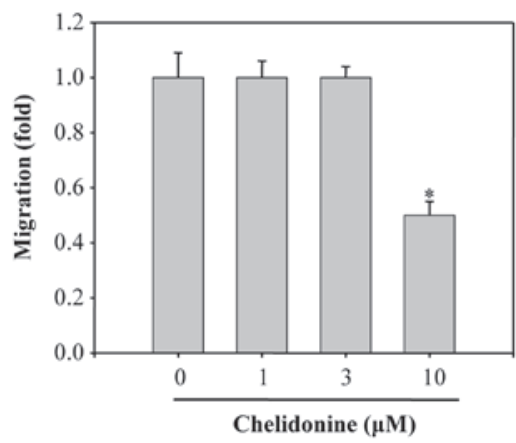

Figure 2. The effects of chelidonine on the migratory ability of MDA-MB-231 human breast cancer cells. In the migration assay, the lower surface of the filters, in a Boyden chamber, was coated with (A) type 1 collagen (COL-I) or (B) fibronectin. The cells were treated with the indicated concentrations of chelidonine for 8 (fibronectin) or $12 \mathrm{~h}$ (COL-I). The cells that migrated through the pores in the filter were fixed, stained and counted in five random fields. The data represent the means \pm standard deviation of three independent experiments, performed in triplicate; ${ }^{*} \mathrm{P}<0.01$, as compared with the vehicle-treated control.

sive visible lamellipodia. The results represent the percentage of spread cells in five randomly selected microscopic fields (magnification, x200).

F-actin staining and confocal microscopy. The cells were grown on glass coverslips coated with COL-I, fixed with $4 \%$ paraformaldehyde and permeabilized in $0.2 \%$ Triton X-100. The F-actin staining was performed using fluorescein isothiocyanate (FITC)-conjugated phalloidin. Confocal images were acquired using a Zeiss LSM510 META NLO inverted laser scanning confocal microscope (Carl Zeiss AG, Oberchocken, Germany; Korea Basic Science Institute Chuncheon Center) equipped with an external argon $\mathrm{HeNe}$ laser and $\mathrm{HeNe}$ laser II. The images were captured at the colony midsection using a C-Apochromat 63X NA1.2 water immersion objective (Carl Zeiss AG).

Statistical analyses. The data represent the means \pm standard deviation of three independent experiments, each repeated in triplicate. The data were analyzed by Student's t-test. A $\mathrm{P}<0.05$ was considered to indicate a statistically significant difference, as compared with the controls.

\section{Results}

Chelidonine inhibits COL-I-induced migration of MDA-MB-231 cells without affecting cell viability. The Boyden chamber migration assay was performed to determine 
A

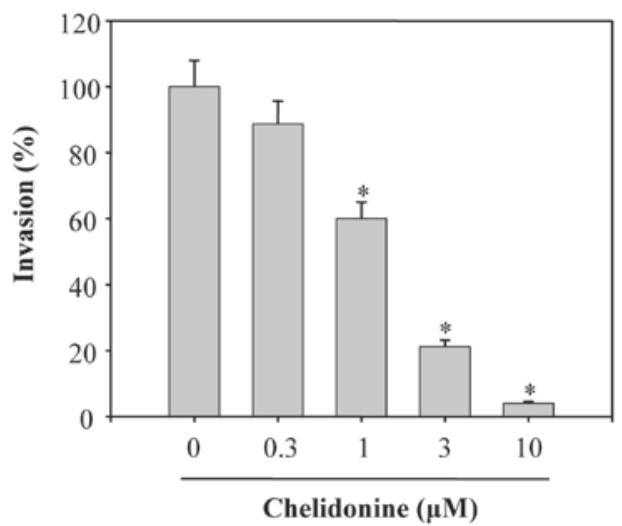

B

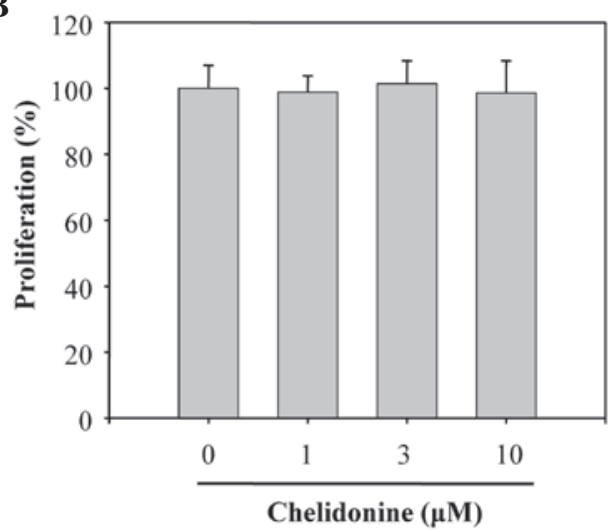

Figure 3. The effects of chelidonine on the invasive ability and viability of MDA-MB-231 human breast cancer cells. (A) The cells were treated with the indicated concentrations of chelidonine for $16 \mathrm{~h}$ in a Boyden chamber invasion assay, and the invasive ability of the cells was quantified by counting the number of cells that invaded through the underside of the porous polycarbonate membrane. The data represent the average of three independent experiments, performed in triplicate; ${ }^{*} \mathrm{P}<0.01$, as compared with the vehicle-treated control. (B) MDA-MB-231 cells were seeded in triplicate in 96-well plates and cultured with the indicated concentrations of chelidonine for $24 \mathrm{~h}$. The viability of the cells was determined using an MTT assay. The data represent the means \pm standard deviation of three independent experiments, performed in triplicate.

the inhibitory effects of chelidonine on the migratory ability of MDA-MB-231 cells. The lower surface of the filters was coated with COL-I and the migrated cells were analyzed following a $12 \mathrm{~h}$ incubation with chelidonine. Chelidonine significantly suppressed the migration of the cells towards COL-I, in a concentration-dependent manner, with a half maximal inhibitory concentration $\left(\mathrm{IC}_{50}\right)$ value of $1.0 \pm 0.1 \mu \mathrm{M}$ (Fig. $2 \mathrm{~A}$ ). The effects of chelidonine on the migration of MDA-MB-231 cells induced by fibronectin, were also investigated. Chelidonine treatment weakly inhibited the migration of the cells towards fibronectin, with an $\mathrm{IC}_{50}$ value of $>10 \mu \mathrm{M}$ (Fig. 2B). These results suggest that chelidonine was more effective at suppressing COL-I-induced cell migration, as compared with fibronectin-induced cell migration. The present study also examined whether chelidonine was capable of suppressing the invasive abilities of MDA-MB-231 cells, using a Boyden chamber coated with Matrigel ${ }^{\mathrm{TM}}$. The number of cells invading the lower chamber were significantly decreased when the cells were treated with chelidonine, in a concentration-dependent manner, with an $\mathrm{IC}_{50}$ value of $1.4 \pm 0.2 \mu \mathrm{M}$ (Fig. 3A). To verify that the concentrations of chelidonine used in the experiments did not affect the cell viability, MDA-MB-231 cells were incubated with various concentrations of chelidonine for $24 \mathrm{~h}$ and cell viability was evaluated using an MTT assay. Chelidonine did not cause any significant toxic effects on the cells $<10 \mu \mathrm{M}$ (Fig. 3B), suggesting that chelidonine is effective in inhibiting MDA-MB-231 cell migration and invasion.

Chelidonine inhibits cell spreading and actin cytoskeleton reorganization, during adhesion to COL-I. Integrin-mediated cancer cell adhesion and spreading is an important step in cell migration and invasion (22). Therefore, the present study determined whether chelidonine prevented the adhesion of MDA-MB-231 cells to COL-I. Treatment of MDA-MB-231 cells with chelidonine slightly impaired the adhesion of cells to COL-I (Fig. 4A). The percentage of adhesion inhibition, in the cells treated with $10 \mu \mathrm{M}$ chelidonine, was $15 \pm 2.5 \%$, which was markedly less than that of the migratory inhibition towards COL-I. The effects of chelidonine on the spreading of MDA-MB-231 cells on COL-I were also determined. Chelidonine inhibited the spreading of cells on COL-I, in a concentration-dependent manner, with an $\mathrm{IC}_{50}$ value of $2.5 \pm 0.3 \mu \mathrm{M}$ (Fig. 4B). COL-I stimulation also induced a dramatic reorganization of the actin cytoskeleton in MDA-MB-231 cells; however, treatment of the cells with $10 \mu \mathrm{M}$ chelidonine completely blocked the COL-I-induced reorganization of the actin cytoskeleton (Fig. 4C). These results suggest that chelidonine may inhibit migration of MDA-MB-231 cells by suppressing the reorganization of the actin cytoskeleton and cell spreading.

Chelidonine inhibits COL-I-induced activation of Akt. Integrins transmit signals through a variety of intracellular protein kinases and adaptor molecules, including FAK and ILK $(9,23)$. Activation of FAK results in numerous cellular processes, including cell attachment, migration and invasion (24). Therefore, the effects of chelidonine on COL-I-induced FAK activation were determined. COL-I stimulation did not significantly increase the protein expression levels of phospho-FAK (Tyr397) in MDA-MB-231 cells (Fig. 5A). However, COL-I stimulation did significantly increase the protein expression levels of phospho-Akt (Ser473) within $30 \mathrm{~min}$, after which it gradually returned to the basal level (Fig. 5A). These results suggest that the activation of Akt may be induced at an early stage during adhesion to COL-I, in this cancer cell line. Notably, treatment of MDA-MB-231 cells with chelidonine significantly decreased phospho-Akt (Ser473) protein expression levels (Fig. 5B), in a concentration dependent manner (Fig. 5C). Conversely, fibronectin increased the protein expression levels of phospho-FAK (Tyr397), and chelidonine treatment did not significantly alter the fibronectin-induced phosphorylation of FAK (Fig. 5D).

Chelidonine inhibits the COL-I-induced formation of the IPP complex. The IPP complex regulates multiple integrin signaling pathways, including Akt, ERK1/2 and Racl small GTPase $(6,23)$. Therefore, the effects of chelidonine on the COL-I-induced formation of the IPP complex were determined 
A

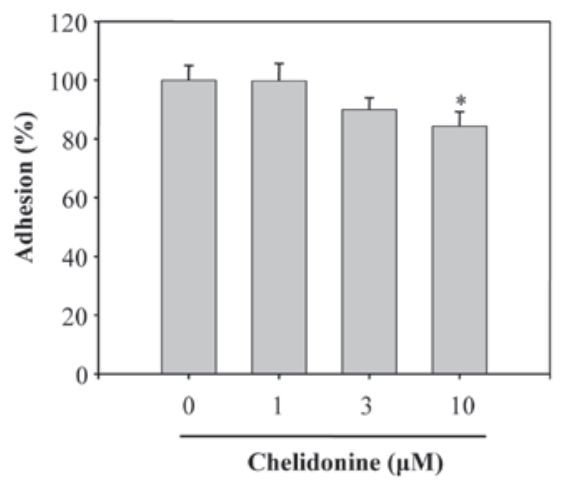

B

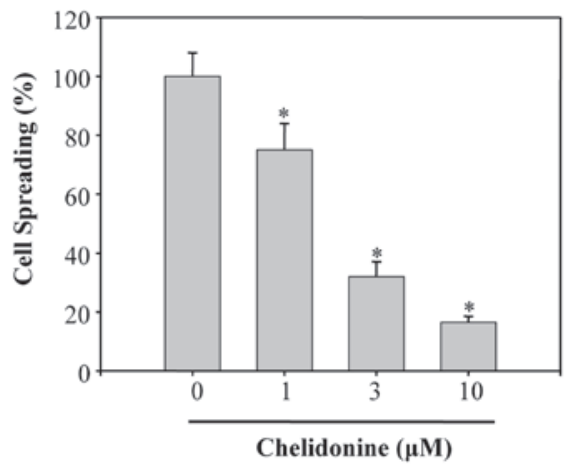

$(+)$ COL-I

C

(-) COL-I

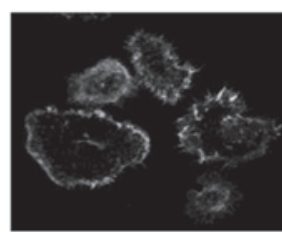

$0 \mu \mathrm{M}$

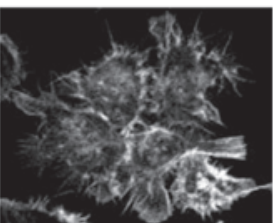

$10 \mu \mathrm{M}$

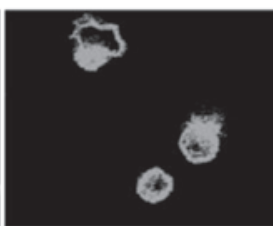

Figure 4. The effects of chelidonine on adhesion, spreading and actin cytoskeletal reorganization of MDA-MB-231 human breast cancer cells. (A) The cells were seeded in triplicate on type 1 collagen (COL-I)-coated 96-well plates and cultured with the indicated concentrations of chelidonine for $1 \mathrm{~h}$. The adhered cells were quantified by measuring the acid phosphatase activity. The data represent the average of three independent experiments, performed in triplicate; ${ }^{*} \mathrm{P}<0.01$, as compared with the vehicle-treated control. (B) The cells were seeded on COL-I-coated 24-well plates and cultured with the indicated concentrations of chelidonine for $1 \mathrm{~h}$. The cells were fixed, visualized by phase-contrast microscopy (magnification, x200) and scored for the percentage of spread cells. The data represent the average of three independent experiments, performed in triplicate; ${ }^{\mathrm{P}}<0.01$, as compared with the vehicle-treated control. (C) The cells were allowed to adhere to COL-I-coated $(10 \mu \mathrm{g} / \mathrm{ml})$ coverslips for $1 \mathrm{~h}$ in the presence or absence of $10 \mu \mathrm{M}$ chelidonine, and stained with fluorescein isothiocyanate-labeled phalloidin, to detect F-actin filaments.

A

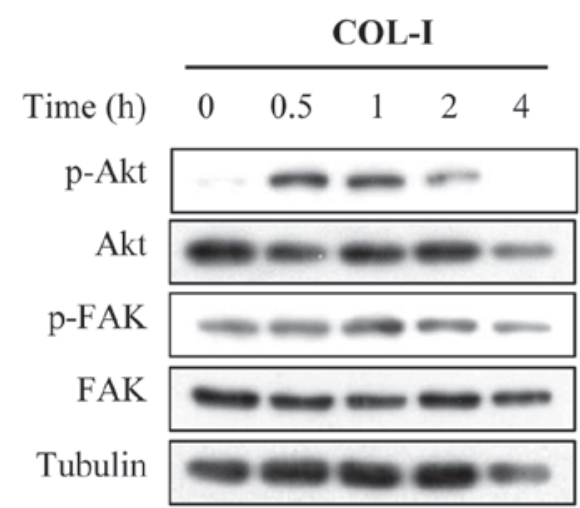

C

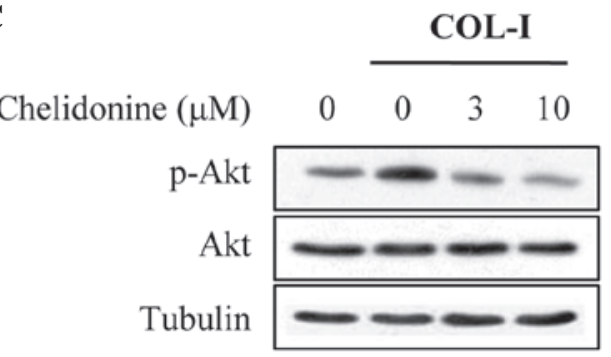

B

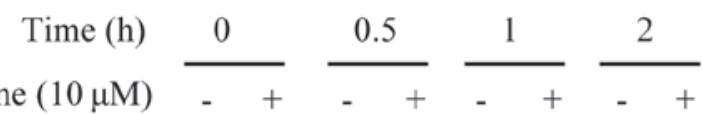

Chelidonine $( 1 0 \mu \mathrm { M } ) \longdiv { - + } + \overline { - + } + \overline { - + }$

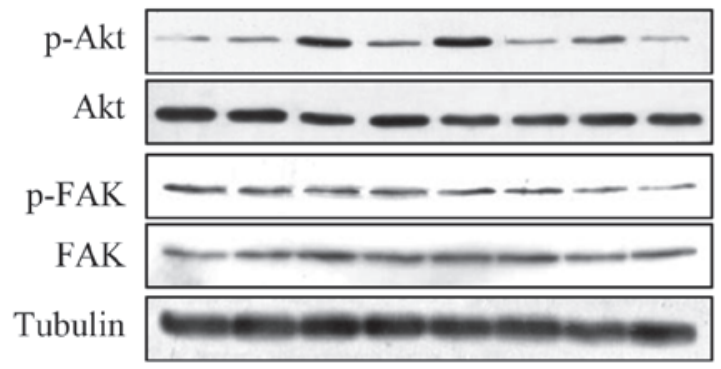

D

Time (h)

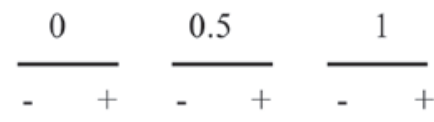

Chelidonine $(10 \mu \mathrm{M})$

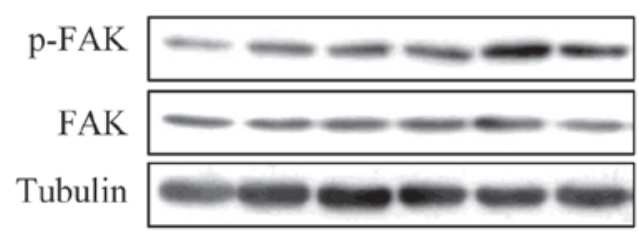

Figure 5. The effects of chelidonine on the activation of Akt and focal adhesion kinase (FAK) in MDA-MB-231 human breast cancer cells. (A) The cells were serum-starved for $12 \mathrm{~h}$ and allowed to adhere to COL-I-coated dishes $(10 \mu \mathrm{g} / \mathrm{ml})$ for the indicated period of time. Whole cell lysates were blotted with the indicated antibodies. (B) The serum-starved cells were allowed to adhere to COL-I-coated dishes $(10 \mu \mathrm{g} / \mathrm{ml})$, in the presence or absence of chelidonine $(10 \mu \mathrm{M})$, for the indicated period of time. Whole cell lysates were blotted with the indicated antibodies. (C) The serum-starved cells were allowed to adhere to COL-I-coated dishes $(10 \mu \mathrm{g} / \mathrm{ml})$, with the indicated concentrations of chelidonine for $1 \mathrm{~h}$. Whole cell lysates were used to determine the protein expression levels of phospho-Akt (Ser473) (p-Akt) by western blot analysis. (D) The serum-starved cells were allowed to adhere to fibronectin-coated dishes (10 $\mu \mathrm{g} / \mathrm{ml}$ ), in the presence or absence of chelidonine $(10 \mu \mathrm{M})$, for the indicated period of time. Whole cell lysates were used to determine the protein expression levels of phospho-FAK (Tyr397) (p-FAK) by western blot analysis. H, hours. 
A

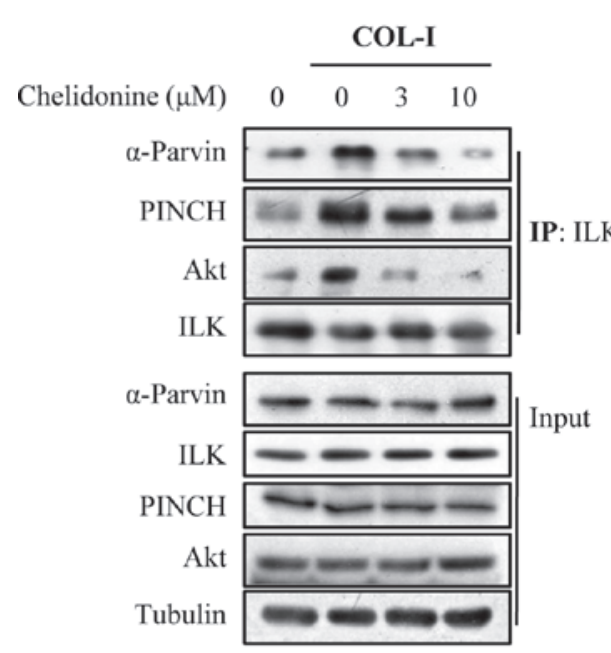

B

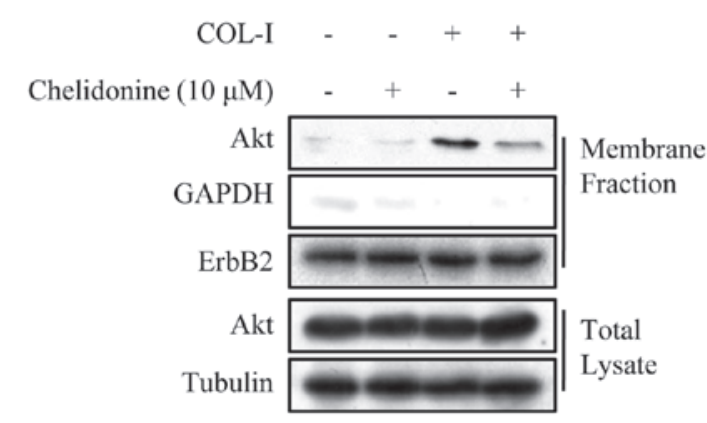

C

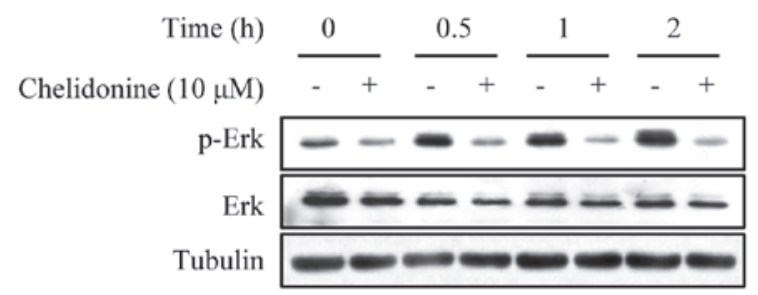

Figure 6. The effects of chelidonine on type 1 collagen (COL-I)-induced formation of the integrin-linked kinase, PINCH and parvin (IPP) complex and translocation of (Akt) to the plasma membrane. (A) The serum-starved MDA-MB-231 human breast cancer cells were allowed to adhere to COL-I-coated dishes, with or without chelidonine $(10 \mu \mathrm{M})$, for $1 \mathrm{~h}$. Whole cell lysates were immunoprecipitated with integrin-linked kinase (ILK) antibody. The immunoprecipitates (IP) and whole cell lysates (Input) were blotted with the indicated antibodies. (B) The serum-starved MDA-MB-231 cells were allowed to adhere to COL-I-coated plates, with or without chelidonine $(10 \mu \mathrm{M})$ for $1 \mathrm{~h}$, and plasma membrane fractions were prepared and blotted with the indicated antibodies. ErbB2 was used as a membrane protein marker, and GAPDH was used as the cytosol protein marker. (C) The effects of chelidonine on COL-I-induced activation of extracellular signal-regulated kinase (ERK)1/2. The serum-starved cells were allowed to adhere to COL-I-coated dishes $(10 \mu \mathrm{g} / \mathrm{ml})$ with the indicated concentrations of chelidonine for $1 \mathrm{~h}$. Whole cell lysates were used to determine the level of phospho-ERK1/2 (p-Erk) by western blot analysis. H, hours.

using a co-immunoprecipitation assay. COL-I stimulation increased ILK association with PINCH1 and $\alpha$-parvin, as well as Akt; however, chelidonine suppressed this association in a concentration-dependent manner (Fig. 6A). Membrane fractionation revealed that chelidonine significantly suppressed the COL-I-induced plasma membrane translocation of Akt (Fig. 6B), which is an essential process for Akt activation $(25,26)$. To further confirm that chelidonine inhibited the COL-I-induced formation of the IPP complex, the effects of chelidonine on IPP downstream signaling molecules, such as ERK1/2, were evaluated. COL-I significantly increased the phosphorylation of ERK1/2 in MDA-MB-231 cells, in a time-dependent manner; however, chelidonine treatment decreased the protein expression levels of COL-I-induced phospho-ERK1/2 (Fig. 6C). These results suggest that chelidonine may exert its anti-migratory effects through interfering with the formation of the IPP complex.

\section{Discussion}

Chelidonium majus has a history in phytomedicine for the treatment of numerous diseases and health disturbances. It contains isoquinoline alkaloids, particularly protoberberine and benzophenanthridine alkaloids (27). The plant extract exhibits both antitumor and antiviral activities (14), in addition to hepatoprotective and anti-genotoxic effects in mice (28). Ukrain, a semi-synthetic derivative of $C$. majus alkaloids, has been used in therapy to treat various types of solid tumor. Previous pre-clinical and clinical investigations have established Ukrain as an anticancer drug (29). Chelidonine, the major component of Ukrain, induces apoptosis (16), mitotic arrest (17) and reduction of telomerase activity (18) in cancer cells. However, the underlying mechanisms behind the anticancer effects of chelidonine remain to be elucidated.

In the present study, the anti-migratory and anti-invasive effects of chelidonine on MDA-MB-231 human breast cancer cells were investigated. The results demonstrated that chelidonine exhibited a potent anti-migratory effect on MDA-MB-231 cells induced by COL-I, without affecting cell viability. Based on these results, the mechanism of action of chelidonine, for inhibiting COL-I-induced migration, was further explored. Chelidonine was shown to be capable of suppressing COL-I-induced reorganization of the actin cytoskeleton and cell spreading. Notably, chelidonine treatment suppressed the formation of the IPP complex and subsequent activation of IPP downstream signaling molecules, including Akt and ERK1/2 induced by COL-I. These results suggest that the anti-migratory mechanisms of chelidonine may be associated with inhibition of integrin signaling, by suppressing the COL-I-induced formation of the IPP complex.

Integrin-mediated signaling regulates a variety of biological processes, including cell migration, survival and proliferation. The ternary IPP complex is also a central constituent of adhesion sites, where it regulates multiple signaling pathways, including Akt, ERK1/2, and Rac1 $(6,8,10)$. The present study demonstrated that chelidonine suppressed the COL-I-induced association of ILK with PINCH1, $\alpha$-parvin and Akt. Furthermore, chelidonine suppressed COL-I-induced reorganization of the actin cytoskeleton, cell spreading and migration, as well as activation of the downstream IPP signaling 
molecules, including Akt and ERK1/2. Therefore, chelidonine may inhibit cell migration by suppressing COL-I-induced integrin signaling, through inhibiting the formation of the IPP complex in MDA-MB-231 cells. However, the detailed mechanisms by which chelidonine interferes with IPP complex formation induced by COL-I, remain to be elucidated.

Chelidonine was shown to be more effective at suppressing COL-I-induced cell migration, as compared with fibronectin-mediated cell migration. The binding of integrins to their ligands induces conformational changes and integrin clustering, resulting in the activation of signaling cascades and recruitment of multi-protein complexes to focal adhesions (30). FAK is predominantly activated in focal adhesions and is important in cell-ECM interactions that affect cell migration, proliferation and survival $(4,7)$. Autophosphorylation of FAK at Tyr397, occurs in response to numerous stimuli, including integrin engagement. FAK phosphorylation promotes the Src homology domain 2-dependent binding of the Src family tyrosine kinases and the formation of an activated FAK-Src complex (7). FAK activation at focal adhesion sites enhances cytoskeletal reorganization, cellular adhesion and cell survival (7). Previous studies have shown that stimulation of MDA-MB-231 cells with fibronectin predominantly induces the activation of FAK $(20,21)$. Conversely, COL-I stimulation does not significantly increase FAK phosphorylation at Tyr397, but induces the activation of Akt in MDA-MB-231 cells, suggesting that the formation of the IPP complex could be induced at an early time during adhesion to COL-I, in this cancer cell line. Chelidonine did not significantly decrease the level of FAK phosphorylation induced by fibronectin, but it did effectively suppress the COL-I-induced formation of the IPP complex, and activation of IPP downstream signaling molecules, including Akt. These results indicate that chelidonine may preferentially inhibit the IPP complex, rather than suppress FAK activation. This may explain why chelidonine was more effective at suppressing COL-I-induced cell migration, as compared with fibronectin-mediated cell migration.

The anticancer effects of chelidonine have previously been reported, however this is the first report, to the best of our knowledge, demonstrating that chelidonine inhibits migration and invasion of MDA-MB-231 cells. These effects may be achieved through the inhibition of the IPP complex and subsequent activation of IPP downstream signaling molecules, such as Akt and ERK1/2. The results of the present study also support potential, additional biological activities of chelidonine, and may provide a basis for the development of more specific cancer chemotherapeutic agents derived from natural products.

\section{Acknowledgements}

The present study was supported by grants from the Leaders in Industry-University Cooperation Project (no. C1011325-01-01), supported by the Ministry of Education, and the National Research Foundation of Korea (no. 2012R1A2A2A06046921).

\section{References}

1. Valastyan S and Weinberg RA: Tumor metastasis: molecular insights and evolving paradigms. Cell 147: 275-292, 2011.
2. Guo W and Giancotti FG: Integrin signalling during tumour progression. Nat Rev Mol Cell Biol 5: 816-826, 2004.

3. Watt FM: Role of integrins in regulating epidermal adhesion, growth and differentiation. EMBO J 21: 3919-3926, 2002.

4. Hynes RO: Integrins: bidirectional, allosteric signaling machines. Cell 110: 673-687, 2002.

5. Hannigan GE, Leung-Hagesteijn C, Fitz-Gibbon L, Coppolino MG, Radeva G, Filmus J, Bell JC and Dedhar S: Regulation of cell adhesion and anchorage-dependent growth by a new beta 1-integrin-linked protein kinase. Nature 379: 91-96, 1996.

6. Legate KR, Montañez E, Kudlacek O and Fässler R: ILK, PINCH and parvin: the tIPP of integrin signalling. Nat Rev Mol Cell Biol 7: 20-31, 2006.

7. Schaller MD and Parsons JT: Focal adhesion kinase and associated proteins. Curr Opin Cell Biol 6: 705-710, 1994.

8. McDonald PC, Fielding AB and Dedhar S: Integrin-linked kinase - essential roles in physiology and cancer biology. J Cell Sci 121: 3121-3132, 2008

9. Fukuda K, Gupta S, Chen K, Wu C and Qin J: The pseudoactive site of ILK is essential for its binding to alpha-Parvin and localization to focal adhesions. Mol Cell 36: 819-830, 2009.

10. Wickström SA, Lange A, Montanez E and Fässler R: The ILK/PINCH/parvin complex: the kinase is dead, long live the pseudokinase! EMBO J 29: 281-291, 2010.

11. Hannigan GE, Leung-Hagesteijn C, Fitz-Gibbon L, Coppolino MG, Radeva G, Filmus J, Bell JC and Dedhar S: Regulation of cell adhesion and anchorage-dependent growth by a new beta 1-integrin-linked protein kinase. Nature 379 : 91-96, 1996.

12. Chiswell BP, Zhang R, Murphy JW, Boggon TJ and Calderwood DA: The structural basis of integrin-linked kinase-PINCH interactions. Proc Natl Acad Sci USA 105: 20677-20682, 2008

13. Hannigan G, Troussard AA and Dedhar S: Integrin-linked kinase: a cancer therapeutic target unique among its ILK. Nat Rev Cancer 5: 51-63, 2005.

14. Colombo ML and Bosisio E: Pharmacological activities of Chelidonium majus L. (Papaveraceae). Pharmacol Res 33: 127-134, 1996.

15. Hohenwarter O, Strutzenberger K, Katinger H, Liepins A and Nowicky JW: Selective inhibition of in vitro cell growth by the anti-tumour drug Ukrain. Drugs Exp Clin Res 18: 1-4, 1992.

16. Kemény-Beke A, Aradi J, Damjanovich J, Beck Z, Facskó A, Berta A and Bodnár A: Apoptotic response of uveal melanoma cells upon treatment with chelidonine, sanguinarine and chelerythrine. Cancer Lett 237: 67-75, 2006.

17. Panzer A, Joubert AM, Bianchi PC, Hamel E and Seegers JC: The effects of chelidonine on tubulin polymerisation, cell cycle progression and selected signal transmission pathways. Eur J Cell Biol 80: 111-118, 2001.

18. Noureini SK and Wink M: Transcriptional down regulation of hTERT and senescence induction in HepG2 cells by chelidonine. World J Gastroenterol 15: 3603-3610, 2009.

19. Park JE, Cuong TD, Hung TM, Lee I, Na M, Kim JC, Ryoo S, Lee JH, Choi JS, Woo MH and Min BS: Alkaloids from Chelidonium majus and their inhibitory effects on LPS-induced NO production in RAW264.7 cells. Bioorg Med Chem Lett 21: 6960-6963, 2011.

20. Hwangbo C, Park J and Lee JH: mda-9/Syntenin protein positively regulates the activation of Akt protein by facilitating integrin-linked kinase adaptor function during adhesion to type I collagen. J Biol Chem 286: 33601-33612, 2011.

21. Hwangbo C, Kim J, Lee JJ and Lee JH: Activation of the integrin effector kinase focal adhesion kinase in cancer cells is regulated by crosstalk between protein kinase Calpha and the PDZ adapter protein mda-9/Syntenin. Cancer Res 70: 1645-1655, 2010.

22. Ridley AJ, Schwartz MA, Burridge K, Firtel RA, Ginsberg MH, Borisy G, Parsons JT and Horwitz AR: Cell migration: integrating signals from front to back. Science 302: 1704-1709, 2003.

23. Hehlgans S, Haase $M$ and Cordes N: Signalling via integrins: implications for cell survival and anticancer strategies. Biochim Biophys Acta 1775: 163-180, 2007.

24. van Nimwegen MJ and van de Water B: Focal adhesion kinase: a potential target in cancer therapy. Biochem Pharmacol 73: 597-609, 2007.

25. Restuccia DF and Hemmings BA: Cell signaling. Blocking Akt-ivity. Science 325: 1083-1084, 2009. 
26. Filippa N, Sable CL, Hemmings BA and Van Obberghen E: Effect of phosphoinositide-dependent kinase 1 on protein kinase B translocation and its subsequent activation. Mol Cell Biol 20: 5712-5721, 2000.

27. Niu CQ and He LY: Determination of isoquinoline alkaloids in Chelidonium majus L. by ion-pair high-performance liquid chromatography. J Chromatogr 542: 193-199, 1991.
28. Biswas SJ, Bhattacharjee N and Khuda-Bukhsh AR: Efficacy of a plant extract (Chelidonium majus L.) in combating induced hepatocarcinogenesis in mice. Food Chem Toxicol 46: 1474-1487, 2008

29. Ernst E and Schmidt K: Ukrain-a new cancer cure? A systematic review of randomised clinical trials. BMC Cancer 5: 69, 2005.

30. Hynes RO. Integrins: bidirectional, allosteric signaling machines. Cell 110: 673-687, 2002. 